\title{
The Effect of Basic Life Skills Training on Adaptability and Psychological Well-Being in Married Female Students
}

\author{
Seyedeh Zahra Sadati ${ }^{1}$, Bahram Mirzaian ${ }^{2 *}$, Yarali Doosti ${ }^{2}$ \\ 1Ph.D. Student of General Psychology, Islamic Azad University, Sari, Sari, Iran \\ ${ }^{2}$ Department of Psychology, Islamic Azad University, Sari, Sari, Iran
}

\begin{abstract}
Background: Effective communication and the establishment of a good communication model among individuals have a prominent role in adaptation and can play an essential role in creating the psychological well being of married students. The purpose of this study was to investigate the effect of basic life skills training on adaptability and psychological well being in married female students. Methods: The present study was a semi-experimental with pre-test and post-test with the control group. A sample of 40 female undergraduate students of Qaemshahr Azad University University in the academic year of 2017-2018 was selected with convenience sampling and divided into 2 experimental and control groups randomly (each group 20 student). The experimental group received eight sessions of basic life skills training in 2 sessions of 90 minutes per week. Control group received no training. In order to collect information, Bell's adaptive scale and psychological well-being questionnaire used. Covariance analysis by SPSS-22 software was used to analyze the data.

Results: results of covariance analysis showed that the training of basic skills of life increased the adaptability $(P<0.001)$ and psychological well-being $(P<0.001)$ in the experimental group compared to the control group at the post-test stage.

Conclusion: According to the results of the current study, it can be used basic life skills training as an effective way to increase the psychological well-being and student adaptability.

Keywords: Basic life skills training; Adaptability; Psychological well-being; Students.
\end{abstract}

*Correspondence to

Bahram Mirzaeian, Faculty of Psychology and Educational Sciences, Islamic Azad University, Sari, Sari, Iran. Tel: 011-33032891.

Email: bmirzaian@iausari.ac.ir

\section{Published online 20 March} 2019

Citation: Sadati SZ, Mirzaian B, Doosti Y. The effect of basic life skills training on adaptability and psychological well-being in married female students. Int Clin Neurosci J. 2019;6(1):28-32. doi:10.15171/icnj.2019.06

\section{Introduction}

Student's life has its challenges besides being married. Confronting with these challenges and good responding to them needs fit adaptability. Many students may be depressed due to many problems. ${ }^{1}$ Addressing these challenges and providing appropriate responses to them requires proper adaptation. Psychologists believe that adaptability consists of all strategies for controlling stressful life situations including actual \& unactual treatments. ${ }^{2}$ The adjusted person may communicate between self and his/her social environment correctly, and its result would be useful to his establishment and emotional stability for himself. Adaptability is an important factor to create temperance in life, and problem-solving, adaptability and coordination with self and its environment are necessary for the human being. ${ }^{3}$ As stated, married students deal with different challenges. Changing in life need's to coordination with situations. Confronting ways with these changes are very various and effect on a person's mental health regarding confronting. Psychological well-being is an important mental feature for a healthy person. Psychological wellbeing is effective upon the person, family and society's growth. Well-being defined as cognitive and affective appraisal from life. ${ }^{4}$ Psychological well-being is a positive affection that defined with satisfaction, enjoyment, and happiness and its symptoms are positive believes about life, positive emotions, and no negative emotions. In other words, psychological well-being thought relaxation that is favorite predictive results for life and improves life's satisfaction. Psychological well-being is necessary to improve life's satisfaction.,

Training effective communication and basic life skills training are known as effective factors upon psychological well-being and adaptability. Training life skills result in discusses students with each other and become organization familiar from each other needs. ${ }^{7}$ The World Health Organization defines the basic skills of life as a positive and adaptive behavior which enables individuals to effectively cope with the challenges. Basic life skills are

(C) 2019 The Author(s). This is an open access article distributed under the terms of the Creative Commons Attribution License (http:// creativecommons.org/licenses/by/4.0/), which permits unrestricted use, distribution, and reproduction in any medium, provided the original work is properly cited. 
individual and social skills that help children and teenagers to behave about self, other persons and whole society effectively. Basic life's skills are used to prevent, control and management of problems individually and by group. ${ }^{8}$ In the last few decades, the topic, which attracted the attention of psychologists and international organizations, is the life basic skills, and it is education that has played an important role in creating a positive attitude towards the life and mental health of humans. ${ }^{9}$ Basic life skills are the necessary skills and methods for having one healthy life. Basic life skills are known as abilities to improve a person's adaptability, positive behavior and self-efficacy, self-assurance, self-esteem and effective communication; They can regard others thoughts, feelings, and rights. By providing such goals, person's mental-social abilities are improved and cause people to take responsibility for their social roles and face the challenges and problems of life without hurting themselves and others and show healthy behaviors in their life. ${ }^{10}$ Different studies have done about life's skills training and their effects. For example, Sharbaf and colleagues 2016 indicated that basic life skills training have been effective upon increasing social adaptability level and decreasing mental disorders. ${ }^{11}$ Also, the study of Rahmati and colleagues in 2010 showed that life skills training have a positive effect on the social adaptability of female students. ${ }^{12}$ Moreover, Hossaini Motlagh et al indicated that basic life skills training had an important effect in improving mental health and marital adaptability in the experimental group than the control group. ${ }^{13}$

Adaptability or nonadaptability subject among students in social, affective and occupational situations are essential among young persons. Nonadaptability is effective upon all dimensions of life and decreases their performance; on the other side, increasing students, adaptability may effect upon their psychological well-being. It seems that cognition of adaptability dimensions and adaptability increasing ways and improving psychological wellbeing among young persons are essential for educational systems. Therefore, executing basic life skills training sessions to improve adaptability and psychological wellbeing among young persons is the benefit. The purpose of this study was to investigate the effect of basic life skills training on adaptability and psychological well-being in married students.

\section{Methods}

The present study was a semi-experimental with pretest and post-test with the control group. A sample of 40 female undergraduate students of Qaemshahr Azad University in the academic year of 2017-2018 with a low level of psychological well-being and adaptability were selected with convenience sampling and randomly divided into two experimental and control groups (each group 20 student). At first, the pre-test has done. After that, the experimental group received eight sessions of basic life skills training in 2 sessions of 90 minutes per week. The control group received no training. After finishing the therapy period, all two groups participated in the posttest. Inclusion criteria consisted of female sex and being married, marriage time more than 2 years, low score in adaptability \& psychological well-being questionnaire, informed satisfaction to participate at research, and exclusion criteria consisted: Having a severe physical illness, neurological and psychiatric disorders, recent participation at similar interventional program and being absent more than 2 sessions. The participants were provided with explanations about the research objectives and also assured them that the information would be confidential. Informed consent obtained from all the subjects. In order to collect information, the bell's adaptive scale and psychological well-being questionnaire used. In this research, Covariance analysis and SPSS-22 software were used to analyze the data.

\section{Bell's Adaptive Questionnaire}

This questionnaire designed by the bell in 1961 and consists of family adaptability, occupational adaptability, health adaptability, effective adaptability, and social adaptability. The test has 160 questions with three choices (Yes/No/I do not know). Yes, the choice item has one score, and no choice item has o score. The whole acquired score is used to show the general situation of adaptability. High scores indicate no favorite adaptability and lower scores mean optimal compatibility. Test-retest reliability at guidance has been $0.70-0.93$, and internal consistency coefficient has been $0.74-0.93 .{ }^{14}$ Validity coefficient for family adaptability, health adaptability, effective adaptability, occupational adaptability and for all test have been reported $0.91,0.81,0.88,0.91,0.85$ and 0.94 by bell orderly. ${ }^{14}$ Also, this scale has indicated high validity to identify standard groups from neurotic groups. Michaeli and Emamzadeh have stated this test reliability and its validity 0.84 and 0.80 orderly. ${ }^{15}$

\section{Ryff Psychological Well-Being Scale}

Ryff designed this scale in 1980. The basic form consists of 120 questions, but at later studies shorter forms 84 questions, 54 questions, and 18 questions have been prepared. Eighteen questions form used in this research. Responding to each question is identified upon one 6 degrees scale (from completely disagree (6) to completely agree (1)). Higher scores indicate better psychological well-being and vice versa. ${ }^{16}$ In the current study, testretest reliability method showed its reliability and was $85 \%$ by Cronbach $a$ that indicates acceptable validity and reliability.

\section{Results}

The frequency of subjects' age included that: 19 persons (21-24 aged), 14 persons (25-28 aged) and seven persons (29-35 aged) and all of them were married. Descriptive findings consist of mean, the standard deviation of 
Table 1. Summary of Sessions Related to Life Basic Skills Training Period

\begin{tabular}{ll}
\hline Sessions & Subject \\
\hline Session 1 & Effective communication skill training and interpersonal communications skill \\
Session 2 & Self-awareness skill training \\
Session 3 & Training of confronting skill against emotion \\
Session 4 & Problem-solving skill training/decision-making skill \\
Session 5 & Confronting skill training against stress \\
Session 6 & Creative thought skill \\
Session 7 & Criticizing thought skill \\
Session 8 & Empathy skill, executing posttests and reviewing sessions \\
\hline
\end{tabular}

the adaptability and psychological well-being score of experimental and control groups at pretest \& posttest stages have presented in Table 2.

The Kolmogorov-Smirnov test was used to test the distribution of variables, and the results showed that the distribution of scores in both experimental and control groups was normal $(P>0.05)$. Also, Levin test results to study the presumption of two groups variances equality for adaptability variable $(\mathrm{F}=0.29 ; P=0.58)$ and psychological well-being $(\mathrm{F}=0.25 ; P=0.62)$ indicated variances equality

Table 2. Mean, the Standard Deviation of Adaptability and Psychological Well-Being for Experimental and Control Groups at Pretest and Posttest Stages

\begin{tabular}{lllll}
\hline Variable & Stage & Group & Mean & SD \\
\hline \multirow{4}{*}{ Adaptability } & \multirow{2}{*}{ Pretest } & Experimental & 60.95 & 6.48 \\
& & Control & 56.08 & 5.73 \\
& \multirow{2}{*}{ Posttest } & Experimental & 42.00 & 6.50 \\
& & Control & 55.05 & 5.59 \\
Psychological & \multirow{2}{*}{ Pretest } & Experimental & 65.67 & 5.48 \\
Well-being & & Control & 64.65 & 5.68 \\
& \multirow{2}{*}{ Posttest } & Experimental & 79.68 & 6.68 \\
& & Control & 64.60 & 5.76 \\
\hline
\end{tabular}

presumptions correctness.

Covariance analysis was used to study the effect of life skills training upon adaptability, and psychological wellbeing of subjects and its results presented in Table 3. Regarding table 3 , there is a significant difference between the experimental and control group $(P<0.001)$. On this basis, we can state that there is a significant difference between two groups at least in one of the dependent variables (adaptability and psychological well-being). ANCOVA analysis was executed to study this difference. Its results have presented in Table 4.

According to presented means and significance level, we can state that life skills training may increase adaptability and psychological means at post-test. This difference was significant for experimental and control groups $(P<0.001)$. This training is effective upon adaptability and psychological well-being among subjects in experimental groups. The effective rate upon adaptability and psychological well-being were 0.81 and 0.69 orderly. In other words, $81 \%$ adaptability variance and $69 \%$ psychological well-being variance were a result of life skills training.

Table 3. Results of Covariance Results to Study the Effect of Life Skills Training Upon Adaptability and Psychological Well-Being of Subjects

\begin{tabular}{llllllll}
\hline Test & Value & F & Df $_{\text {Hypothesis }}$ & Df $_{\text {error }}$ & Effect value & Statistical Potency & $\boldsymbol{P}$ \\
\hline Pillay effect & 0.87 & 91.83 & 2 & 27 & 0.87 & 1 & $<$ \\
Wilkz lambda & 0.12 & 91.83 & 2 & 27 & 0.87 & 1 & $<0.001$ \\
Hotelling effect & 6.81 & 91.83 & 2 & 27 & 0.87 & 1 & 1 \\
Roy's largest root & 6.81 & 91.83 & 2 & 27 & 0.87 & $<0.001$ \\
\hline
\end{tabular}

Table 4. Acquired Results From ANCOVA Analysis Within MANCOVA Upon the Mean Difference of Adaptability and Psychological Well-Being Pretest-Posttest Scores for Experimental and Control Groups

\begin{tabular}{|c|c|c|c|c|c|c|c|c|}
\hline Variables & Source & SS & Df & MS & $\mathbf{F}$ & Effect Value & Statistical Potency & $\mathbf{P}$ \\
\hline \multirow{3}{*}{$\begin{array}{l}\text { Psychological } \\
\text { Well-being }\end{array}$} & Group & 2645.333 & 1 & 2465.333 & \multirow{3}{*}{62.762} & \multirow{3}{*}{0.69} & \multirow{3}{*}{1} & \multirow{3}{*}{$<0.001$} \\
\hline & Error & 10998.667 & 37 & 392.810 & & & & \\
\hline & Total & 76722 & 40 & 2557.4 & & & & \\
\hline \multirow{3}{*}{ Adaptability } & Group & 4813.333 & 1 & 4813.333 & \multirow{3}{*}{167.517} & \multirow{3}{*}{0.81} & \multirow{3}{*}{1} & \multirow{3}{*}{$<0.001$} \\
\hline & Error & 804.533 & 37 & 28.733 & & & & \\
\hline & Total & 14220 & 40 & 47.33 & & & & \\
\hline
\end{tabular}




\section{Discussion}

The purpose of this study was to investigate the effect of life basic skills training on adaptability and psychological well-being in married female students. The present study results indicated that basic life skills training have been effective upon married women adaptability increasing. This result is consistent with Joseph, ${ }^{17}$ Kacker \& Chhadva, ${ }^{18}$ Yadav \& Iqbal, ${ }^{19}$ Mirdrickvand et $\mathrm{al}^{20}{ }^{20}$ and Hatami \& Kavousian. ${ }^{21}$ We can state that one of the most important results life skills increasing is helping to person's adaptability. Adaptability is effective communication with the environment, and two processes occur simultaneously: (1) Making coordinating self with situations, and (2) Situations change to adapt to needs. ${ }^{22}$ Therefore, this training help to identify effects and feelings, to appraise them carefully, understand logical and illogical thoughts and finally they find that effective and ineffective thoughts, positive and negative effects control them. When subjects understand that their imaginations affect upon emotions and positive \& negative effects, therefore they control them with learned skills and effective adaptability is created. We can state that better affective adaptability at posttest is a successful result of this function. ${ }^{21}$ Basic life skills training in improving social adaptability has been effective. Life skills training help people to understand many of their psychological characteristics. Also, in the process of skills training, persons are informed that there are differences between them and others that should be accepted and continue with these differences. Group conformity with life skills helps to have a peaceful life.$^{20}$ It seems that students in the experimental group have been evaluating their mental beliefs during their education and these training help them to adapt successfully to their environment and inner world. They may control their stress by these skills, identify self-better, understand problems, and select fit solves. They finally adapt with others and follow actual goals in life. Finally, they have a healthy and consistent personality and pursue the real and rational goals of life. Also, the present study results indicated that life skills training had had an important effect on improving student's psychological well-being. The results of this study are consistent with Sidwell et al 2018, ${ }^{23}$ Marhamati et al, ${ }^{24}$ Ghasemian and Kumar, ${ }^{25}$ Hossaini Motlagh et al, ${ }^{13}$ Solati, ${ }^{8}$ Khodabandeluo et al, ${ }^{26}$, and Khaledian. ${ }^{27}$ In explaining these results, it can say, life skills training results in learning assertive and skill of feeling by married students. Assertive express of feeling makes intimacy couples with each other and helps to express their feeling toward his/her spouse that results in improving mental health and well-being for both of them..$^{28}$ Also, couples with learning the decision-making skills and problem-solving, when they faced the problems in their marital life or when they require very important decision-making, they can adopt more appropriate strategies, and they were satisfied from their high living standards. Learning problem-solving skill by couples and using different situations help to deal with their problems instead of retirement from them. Therefore, these couples are less likely to suffer from mental disorders. ${ }^{29}$ We can state that life skills training results in having a positive feeling, higher self-acceptance, better communication among self and others or environment and finally believe in developing individually. Also, these abilities increase their control upon the environment and finally using these skills result in their individual growth. ${ }^{30}$

\section{Conclusion}

Although generalizing this study results needs to more researches, but we can state that basic life skills training may increase a person's abilities significantly that may prevent behavioral and emotional disorders positively; therefore we suggest that basic life skills training should be important for educational specialists.

\section{Conflict of Interest Disclosures}

The authors declare that they have no conflict of interests.

\section{Ethical Statement}

All ethical principles were considered in this article. The participants were informed about the purpose of the research and its implementation stages and signed the informed consent; they were also assured about the confidentiality of their information; Moreover, They were allowed to leave the study whenever they wish, and if desired, the results of the research would be available to them.

\section{References}

1. Rezaei T, Yazdi-Ravandi S, Ghaleiha A, Seif Rabiei MA. Depression among medical students of Hamadan University of Medical Sciences in 2014: The Role of demographic variables. Pajouhan Scientific Journal. 2015;13(4):1-8.

2. Yazdi-Ravandi S, Taslimi Z, Ahmadpanah M, Ghaleiha A. Adjustment to diabetes among diabetic patients: the roles of social support and self-efficacy. Avicenna Journal of Neuro Psycho Physiology. 2016;3(1):1-5.

3. Pourrazavi S, Hafezian M. The Effectiveness of teaching positive thinking skills on social, emotional, and academic adjustment of high school students. J Sch Psychol. 2017;6(1):26-47. doi: 10.22098/jsp.2017.536.

4. Fernandez-Berrocal P, Extremera N. Ability emotional intelligence, depression, and well-being. Emot Rev. 2016;8(4):311-5. doi: 10.1177/1754073916650494.

5. Diener E, Oishi S, Lucas RE. Personality, culture, and subjective well-being: emotional and cognitive evaluations of life. Annu Rev Psychol. 2003;54:403-25. doi: 10.1146/ annurev.psych.54.101601.145056.

6. Yazdi-Ravandi S, Taslimi Z, Haghparast A, Ghaleiha A. Quality of life in patients with chronic pain disorders: Determinnation the role of intensity and duration of pain. Koomesh. 2016;17(4):836-43.

7. Arora V, Bala M, Chawla S. Impact of Additional Short Session of Video Training on Performance of Basic Life Support Skills in 2(nd)-Year Medical Students. Indian J Crit Care Med. 2018;22(7):498-502. doi: 10.4103/ijccm.IJCCM_94_18.

8. Solati K. The effectiveness of life skills training on happiness, mental health, and marital satisfaction in wives of IranIraq war veterans. Middle East Journal of Family Medicine. 
2017:15(7):74-82 doi: 10.5742/MEWFM.2017 93038.

9. Chiang HM, Ni X, Lee YS. Life Skills Training for Middle and High School Students with Autism. J Autism Dev Disord. 2017;47(4):1113-21. doi: 10.1007/s10803-017-3028-1.

10. Adeniyi SO, Anyama SC. Relationship between life building skills and social adjustment of students with hearing impairment: Implications for counseling. J Spec Educ Rehabil. 2017;18(3-4):25-43. doi: 10.19057/jser.2017.24.

11. Sharbaf Olyaie Z, Toozandehjani H, Kiafar Z. The Effectiveness of Life Skills Training on Social Adjustment and Mental Disorders in Foster Kids and Adolescents. Int J Adv Biotechnol Res. 2016;7(4):634-8

12. Rahmati B, Adibrad N, Tahmasian K, Saleh Sedghpour B. The effectiveness of life skill training on social adjustment in children. Procedia Soc Behav Sci. 2010;5:870-4. doi: 10.1016/j.sbspro.2010.07.201.

13. Hossaini Motlagh A, Alizadeh Z, Shahabadi S. The Effect of Life Skills Training on Mental Health and Marital Adjustment in Married Women Referred to the Counseling Center in Yasuj (2013). Biomed Pharmacol J. 2016;9(2):513-517. doi: 10.13005/bpj/966.

14. Bell HM. The adjustment inventory: student form. Palo Alto, CA: Consulting Psychologists Press; 1962.

15. Michaeli Manee F, Madadi Emamzadeh Z. Study of relationship between emotional-social intelligence with social adjustment among students with disciplinary commandment and their comparison students without it in Urumia University. Journal of Psychology. 2008;3(11):99-121.

16. Ryff $C D$, Singer BH. Best news yet on the six-factor model of well-being. Soc Sci Res. 2006;35(4):1103-19. doi: 10.1016/j. ssresearch.2006.01.002.

17. Joseph K. Life skills education for adolescents. Mumbai: Better Your-self Books; 2018.

18. Kacker P, Chhadva D. Effectiveness of Life Skill Education on Adolescents. Int J Res Educ Method. 2012;3(1):213-20.

19. Yadav $P$, Iqbal N. Impact of life skill training on self-esteem, adjustment and empathy among adolescents. J Indian Acad Appl Psychol. 2009;35:61-70.

20. Mirdrikvand F, Ghadampour E, Kavarizadeh M. The Effect of Life Skills Training on Psychological Capital and Adaptability of Adolescent Girls with Irresponsible Parents. Quarterly Journal of Social Work. 2016;5(3):23-30.

21. Hatami M, Kavousian J. The effectiveness of life skills training on adjustment (social, educational, emotional) of martyrs children. J Sch Psychol. 2013;2(2):44-55

22. Avison WR, Aneshensel CS, Schieman S, Wheaton B. Advances in the conceptualization of the stress process: Essays in honor of Leonard I. Pearlin. New York: Springer Science \& Business Media; 2009.

23. Sidwell RA, Spilman SK, Huntsman RS, Pelaez CA. Efficient Hemorrhage Control Skills Training for Healthcare Employees. J Am Coll Surg. 2018;226(2):160-4. doi: 10.1016/j. jamcollsurg.2017.11.003.

24. Fouladchang M, Marhemati Z. The Effects of Life Skills Instruction (through Integration of Islamic Perspectives into Psychology) on Psychological Well-Being. Quarterly Journal of Applied Issues in Islamic Education. 2017;2(2):91-112. doi: 10.29252/qaiie.2.2.91.

25. Ghasemian A, Kumar GV. Effect of life skills training on psychological distress among male and female adolescent students. Indian Journal of Health and Wellbeing. 2017;8(4):279-82.

26. Khodabandeluo N, Pouyamanesh J, Azami M. The Effectiveness of Life Skills Training in Psychological Wellbeing and Dare in High School Secondary School Students. International Conference on Humanities, Psychology and Social Sciences; 2015.

27. Khaledian M. The effectiveness of life skills training on mental health and self-esteem of individuals addicted to drugs. Journal of Social Psychology. 2017:29(2):1-15. [Persian].

28. Heizomi H, Allahverdipour H, Asghari Jafarabadi M, Safaian A. Happiness and its relation to psychological well-being of adolescents. Asian J Psychiatr. 2015;16:55-60. doi: 10.1016/j. ajp.2015.05.037.

29. Hita CR, Kumar GV. Effect of Life Skills Training on Emotional Distress: A Comparative Study between Adolescent Boys and Girls. Int J Indian Psychol. 2017;5(1):145-55.

30. Huppert FA. Psychological well-being: Evidence regarding its causes and consequences. Appl Psychol Health Well Being. 2009;1(2):137-64. doi: 10.1111/j.1758-0854.2009.01008.x. 